\title{
Early childhood screen time as a predictor of emotional and behavioral problems in children at 4 years: a birth cohort study in China
}

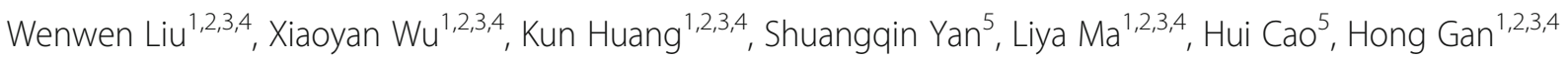
and Fangbiao $\operatorname{TaO}^{1,2,3,4^{*}}$ (D)

\begin{abstract}
Background: Previous studies have suggested that screen time (ST) has a negative effect on children's emotional and behavioral health, but there are few longitudinal studies that have been conducted with infants and toddlers. This study sought to examine the effect of ST in early childhood on emotional and behavioral problems in children aged 4 years, based on a birth cohort study in China.

Methods: A total of 2492 children aged 4 years were enrolled in this study. The parents and guardians of each child completed a questionnaire that included items eliciting information on children's birth information, sociodemographic information at baseline, and ST at each follow-up. Emotional and behavioral problems were assessed using the Strengths and Difficulties Questionnaire (SDQ) at 4 years of age. Multivariate logistic analysis was used to explore the effects of ST on emotional and behavioral problems.

Results: The percentages of children with ST $>0$ h/day at age 0.5 years, ST $>2 \mathrm{~h} /$ day at age 2.5 years, and ST $>2 \mathrm{~h} /$ day at age 4 years were $45.7,55.5$, and $34.5 \%$ respectively. The prevalence of emotional and behavioral problems was $10.8 \%$. ST at 6 months was a risk factor for emotional symptoms and hyperactivity at the age of 4 years. ST at age 2.5 years was a risk factor for hyperactivity at the age of 4 years. However, ST at age 4 years was a risk factor for total difficulties, conduct problems, peer problems, hyperactivity, and prosocial behavior.

Conclusions: Higher ST exposure at early childhood is associated with later emotional and behavioral problems. In particular, sustained high ST exposure is a risk factor for behavioral problems. These findings suggested the importance of controlling ST to prevent the occurrence of emotional and behavioral problems in the early years.
\end{abstract}

Keywords: Screen time, Psychological, Emotional and behavioral problems, Infants, Children, Longitudinal study

\footnotetext{
*Correspondence: taofangbiao@126.com

'Department of Maternal, Child, and Adolescent Health, School of Public

Health, Anhui Medical University, No 81 Meishan Road, Hefei 230032, Anhui, China

${ }^{2}$ MOE Key Laboratory of Population Health Across Life Cycle, No 81 Meishan Road, Hefei 230032, Anhui, China

Full list of author information is available at the end of the article
}

(c) The Author(s). 2021 Open Access This article is licensed under a Creative Commons Attribution 4.0 International License, which permits use, sharing, adaptation, distribution and reproduction in any medium or format, as long as you give appropriate credit to the original author(s) and the source, provide a link to the Creative Commons licence, and indicate if changes were made. The images or other third party material in this article are included in the article's Creative Commons licence, unless indicated otherwise in a credit line to the material. If material is not included in the article's Creative Commons licence and your intended use is not permitted by statutory regulation or exceeds the permitted use, you will need to obtain permission directly from the copyright holder. To view a copy of this licence, visit http://creativecommons.org/licenses/by/4.0/ The Creative Commons Public Domain Dedication waiver (http://creativecommons.org/publicdomain/zero/1.0/) applies to the data made available in this article, unless otherwise stated in a credit line to the data. 


\section{Background}

Emotional and behavioral problems are common psychological behavior deviation in childhood [1]. Approximately 10 to $20 \%$ of children and adolescents worldwide have one or more mental health problems, accounting for a significant portion of the global burden of childhood diseases [2]. Mental health problems not only reduce the health-related quality of life of children, but also continue to affect them throughout adult life $[3,4]$. Many factors influence the mental health of children and adolescents, such as nighttime sleep duration [5], screen time (ST) [6], and physical activity [7]. Specifically, ST has been identified to be an important risk factor for the healthy growth of children.

With the development of the social economy, the use of various electronic products is increasingly entering the daily lives of people, and children are inevitably being exposed to electronic screens at earlier ages. The ST of children is increasing worldwide [8, 9], despite recommendations of the American Academy of Pediatrics (AAP) that children under 2 years old should avoid digital media use and that the ST of children older than 2 years should be limited to $2 \mathrm{~h} /$ day [10]. Mounting evidence has documented that many children start using screen media devices in infancy and increase their such media throughout childhood [11]; most children are already exposed to electronic screens at 6 months of age [12]. International statistics from 40 countries in Europe and North America show that more than $60 \%$ of children watch television for more than $2 \mathrm{~h} /$ day [13]. A survey of children aged 3 to 6 in 35 kindergartens in China revealed that $57.3 \%$ of the children were exposed to electronic screens exposed for more than $2 \mathrm{~h}$ /day [5]. Overexposure to screens in early childhood has become a common phenomenon, and its subsequent impact on children's health is widespread, enough to warrant our attention.

There is a growing body of evidence which demonstrated that higher levels of ST are associated with negative emotional and behavioral problems in children and adolescents [14-16]. It is widely known that children are in a critical period of growth and development, especially in the first few years of their lives, with considerable plasticity [17]. Given that most of the infants are now exposed to the screen early in life [12], exploring their impact on the later healthy development of children is warranted. To date, most studies have focused on the association between school-age children and adolescents' ST and their mental health. A small but growing number of studies have found the associations between ST and emotional and behavioral problems in infants and young children, such as a birth cohort study in Singapore found that infant television viewing has a negative association with cognitive skills at 4.5 years of age [18].
Many studies on ST apply cross-sectional designs, and longitudinal research is limited. Longitudinal studies are needed to identify such associations from early childhood to later childhood. Thus, the main purpose of the present study was to evaluate the association between ST in infants and toddlers with emotional and behavioral problems in a birth cohort study. We hypothesized that a high ST level in early childhood is a risk factor for emotional and behavioral problems. Furthermore, our birth cohort study design enabled us to examine the associations between sustained ST exposure and emotional and behavioral problems.

\section{Methods \\ Study design and sample}

The children in this study were obtained from the Ma'anshan Birth Cohort (MABC) prospective cohort study, which was conducted in the city of Ma'anshan, Anhui province, China. Details on the procedures for the recruitment and exclusion of pregnant women have been described in previous research [19]. The MABC recruited 3474 pregnant women between May 2013 and September 2014. Children delivered by pregnant women enrolled in the cohort were automatically entered into the cohort for regular follow-ups. Questionnaires that included items from the Strengths and Difficulties Questionnaire (SDQ) as well as items on ST were distributed by maternal and child healthcare professionals when the children were examined at the ages of $0.5,2.5$, and 4 years respectively. At age 4 years of age, 2758 children remained in the survey. More than $30 \%$ of the blanks in the questionnaire were deemed invalid and eliminated, and incomplete SDQs and birth information were also directly excluded. The data of the final sample of 2490 children were obtained (Fig. 1), which included 1289 boys $(51.8 \%)$ and 1201 girls (48.2\%). Informed consent was obtained from the parents and guardians of the participants and the research protocol was approved by the ethics committee of the Anhui Medical University (Ethical approval number: 2008020).

\section{Exposure variables}

Children's ST was reported by their parents and guardians. The current study used two items to investigate the ST of infants aged 0.5 years: "How many hours does the child spends on average every day: (1) watching television and (2) using electronic products (mobile phones, tablets, computers, etc.)?". Meanwhile, three items were used to investigate the ST of children aged 2.5 years: "How many hours does the child spends on average every day in the last month: (1) watching television? (2) using a cell phone? (3) using electronic products (computers or other electronic devices)?". Total ST at the ages of 0.5 and 2.5 years were the sum of the values 


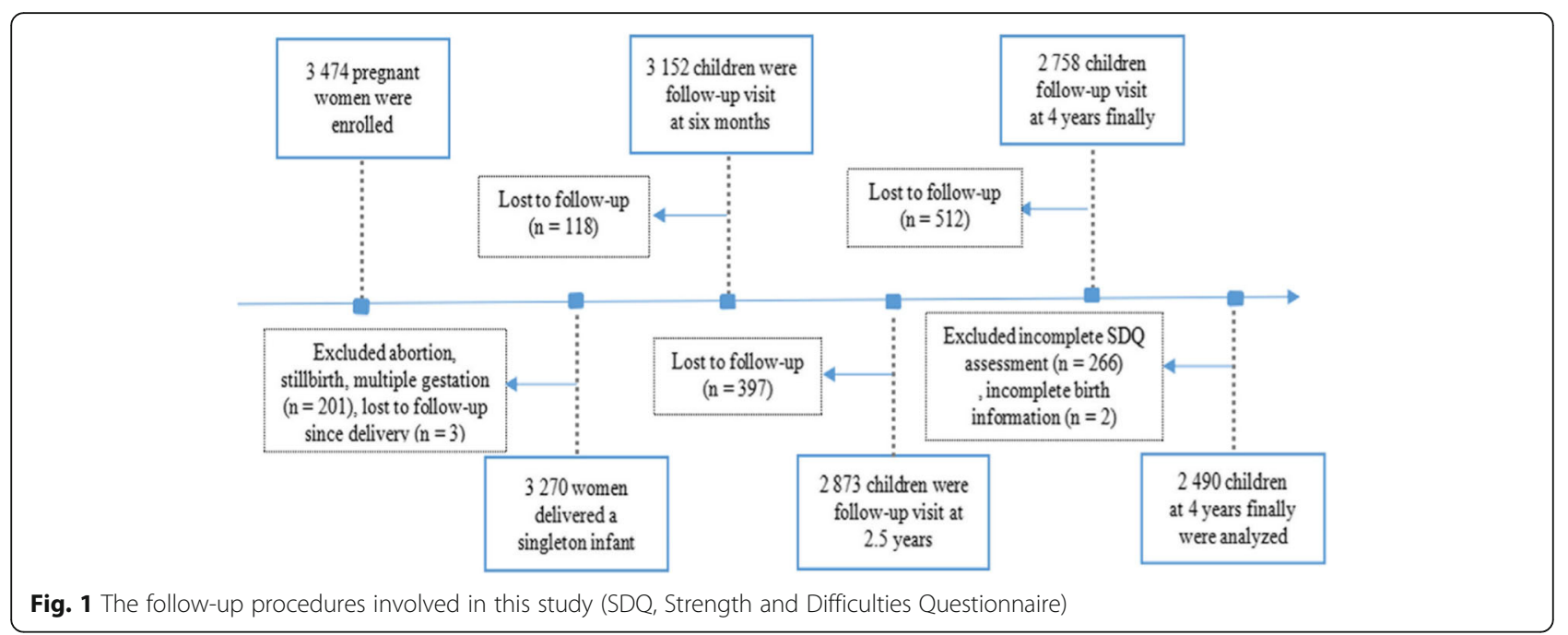

obtained for each item. The ST of children aged 4 years was obtained using the following items: "How many hours does the child spends: (1) watching television? (2) using computer? (3) using a cell phone? (4) using an iPad? (5) using other electronic devices?". Specific hours and minutes were reported. These questions were repeated for weekdays and weekends. The total ST at age 4 years of age was the sum of the time spent on televisions, computer, cell phone, iPads, and other electronic device time during weekdays and weekends. The average daily ST was calculated using the formula $(5 / 7 \times[\mathrm{ST}$ on weekdays $]+2 / 7 \times[$ ST on weekends $]$ ). At the age of 0.5 years, an ST of $0 \mathrm{~h} /$ day was categorized as low and an ST of $>0 \mathrm{~h} /$ day high, while at the ages of 2.5 years and 4 years, an $\mathrm{ST}$ of $\leq 2 \mathrm{~h} /$ day was categorized as low and an ST of $>2 \mathrm{~h}$ /day high, according to the recommendation of the AA P[10].

Continuous high ST was defined as an ST $>0 \mathrm{~h}$ /day at age 0.5 years, $\mathrm{ST}>2 \mathrm{~h}$ /day at age 2.5 years, and $\mathrm{ST}>2$ $\mathrm{h}$ /day at age 4 years; continuous low ST was defined as $\mathrm{ST}=0 \mathrm{~h} /$ day at age 0.5 years, $\mathrm{ST} \leq 2 \mathrm{~h} /$ day at age 2.5 years, and $\mathrm{ST} \leq 2 \mathrm{~h} /$ day at age 4 years.

\section{Outcomes}

The Strengths and Difficulties Questionnaire (SDQ) was completed by the parents and guardians to report on their children's emotional and behavioral problems at age 4 years of age. The SDQ comprises 25 items. The possible scores of each item are scored as 0 ("not true"), 1 ("partialy true"), and 2 points ("completely true"), respectively. The questionnaire is divided into five dimensions: emotional symptoms, conduct problems, hyperactivity/attention deficit, peer problems, and prosocial behavior. The total difficulties' score ranging from 0 to 40 is obtained using the sum of the scores on emotional symptoms, conduct problems, hyperactivity/ attention deficit, and peer problems, with a higher score indicating a represents the higher the degree of objective difficulty. According to the cutoff scores adopted by Goodman et al. [20], children with total difficulties scores between 0 and 13 are defined as normal, 14 and 16 borderline, and 17 and 40 abnormal. For the subscales, the following cut-off values were applied: emotional problems: $0-3=$ normal, $4=$ borderline, $5-10=$ abnormal; conduct problems: $0-2=$ normal, $3=$ borderline, $4-10=$ abnormal; hyperactivity/inattention: $0-5=$ normal, $6=$ borderline, $7-10=$ abnormal; peer problems: $0-2=$ normal, $3=$ borderline, $4-10=$ abnormal; and prosocial behavior: $6-10=$ normal, $5=$ borderline, $0-4=$ abnormal. We divided the scores of each subscale into normal (including normal and borderline categories) and abnormal groups. The internal consistency of the total difficulties score was good (Cronbach's $\alpha=$ 0.784 ), as demonstrated in a previous study in China [21].

\section{Covariates}

The socio-demographic variables of our study were as follows: age, gender (male or female), presence of siblings (yes or no), maximum educational level of parents (which was classified as the highest educational level of the parent who had more formal education; high school or less, college or 2-year degree, and bachelor's or above), family income (<2500 CNY/month, 2500-4000 $\mathrm{CNY} /$ month, > $4000 \mathrm{CNY} /$ month), passive smoking (yes or no), outdoor activities $(<2 \mathrm{~h} /$ day, $\geq 2 \mathrm{~h} /$ day $)$. In addition, information on the birth of the children was also reported. These variables included gestational weeks (full term or premature), delivery mode (vaginal delivery or cesarean section), and birth weight (small for gestational age, appropriate for gestational age, and large for gestational age). 


\section{Statistical analysis}

Chi-square tests were performed to test for the prevalence of prevalence of emotional and behavioral problems. Multiple logistic regression models were used to explore the independent associations between the ST at each age group and the SDQ scores. In additional analyses, the study examined the associations between sustained ST and emotional and behavioral problems which were also analyzed, which were dichotomized into normal (including normal and borderline categories) and abnormal groups. Meanwhile, the analysis was controlled for some potential confounders including gender, age, number of siblings, maximum educational level of parents, family income, passive smoking, outdoor activities, delivery mode, and birth weight. Data analysis were analyzed using the software SPSS, version 23.0. $P<0.05$ was considered statistically significant.

\section{Results}

\section{Characteristics of the sample}

The distribution of the SDQ total and subscale in the sample are presented in Table 1. The abnormal proportion of total difficulties, emotional symptoms, conduct problems, hyperactivity, peer problems, and prosocial behavior were $10.8,8.4,9.8,16.2,26.1$, and $12.1 \%$, respectively. The abnormal proportion of emotional symptoms in girls was higher than in boys, while the abnormal proportion of total difficulties, conduct problems, hyperactivity problems, peer problems, and prosocial behavior in boys were higher than in girls. Children with low parental education levels and exposure to passive smoking were more likely to report emotional and behavioral problems.

\section{Associations between ST and follow-up emotional and behavioral problems}

Table 2 reports the odds ratio of the relationship between ST and emotional and behavioral problems. The percentages of children with $\mathrm{ST}>0 \mathrm{~h} /$ day at age 0.5 years, $\mathrm{ST}>2$ $\mathrm{h}$ /day at age 2.5 years, and $\mathrm{ST}>2 \mathrm{~h}$ /day at age 4 years were $45.7,55.5$, and $34.5 \%$ respectively. The normal group was used as the control group. After adjusting for confounding factors, the high level of ST ( $>0 \mathrm{~h} /$ day) at age 0.5 years was found to be a risk factor for abnormal emotional symptoms and hyperactivity, the high level of ST (> $2 \mathrm{~h}$ /day) at age 2.5 years a risk factor for abnormal hyperactivity, and the high level of ST (> $2 \mathrm{~h}$ /day) at age 4 years a risk factor for abnormal total difficulties, conduct problems, peer problems, hyperactivity, and prosocial behavior.

\section{The gender difference between ST and emotional and behavioral problems}

The gender differences between ST and the abnormal of emotional and behavioral problems are shown in Table 3.
There were a positive associations between ST at age 0.5 years and emotional symptoms (OR $=1.55$, 95\% CI 1.042.32 ), conduct problems (OR $=1.54,95 \%$ CI 1.01-2.35) in girls, and hyperactivity ( $\mathrm{OR}=1.36,95 \% \mathrm{CI} 1.02-1.80)$ in boys. The associations between ST at age 4 years and total difficulties $(\mathrm{OR}=1.62,95 \% \mathrm{CI} 1.14-2.30)$, conduct problems $(\mathrm{OR}=1.76,95 \%$ CI 1.22-2.54), hyperactivity $(\mathrm{OR}=$ $1.41,95 \%$ CI 1.05-1.89), peer problems $(\mathrm{OR}=1.43,95 \%$ CI 1.11-1.85), and prosocial behavior $(\mathrm{OR}=1.62,95 \% \mathrm{CI}$ 1.17-2.24) were found in boys, and total difficulties $(\mathrm{OR}=$ $1.89,95 \%$ CI 1.25-2.87) and conduct problems (OR = 1.96, 95\% CI 1.28-3.00) were found in girls. There were no correlation between the ST at age 2.5 years and emotional and behavioral problems in both boys and girls. No gender differences were found in the independent effects of ST on emotional and behavioral problems.

\section{Associations between sustained ST and emotional and behavioral problems}

Children with continuous high ST had a significantly increased risk for the abnormal of total difficulties, conduct problems, hyperactivity, and peer problems compared to children with continuous low ST, and no gender differences were found, either (Fig. 2).

\section{Discussion}

This study demonstrates that high ST at 0.5, 2.5, and 4 years of age may be important predictors of the emotional and behavioral problems at 4 years of age. In addition, sustained high ST is more likely to lead to behavioral problems when compared to with sustained low ST after controlling for potential confounders.

In our study, almost half of the participants were exposed to electronic screens at 6 months of age. The percentages of children who did not follow the recommended of AAP regarding ST at ages 2.5 and 4 years were 55.5 and $34.5 \%$, respectively. The decrease in percentages with increasing age may be due to children entrance kindergarten. Similarly, a British study showed that nearly two thirds of 5-year-old children watch television for 1 to $3 \mathrm{~h} /$ day, while $15 \%$ of them watch television for more than $3 \mathrm{~h} /$ day [9]. The effects of ST on children are extensive, children are still immature and more likely to have emotional and behavioral problems affected by electronic media. Meanwhile, children's emotional and behavioral problems were high (10.8\%) in this Chinese birth cohort, which is inferior to Australia (14\%) [22] and South Korea (11.8\%) [23] and similar to Japan (11\%) [24]. The prevalence of emotional and behavioral problems among preschool children in our study was also higher than in other provinces $(9.6 \%)$ of China [25]. These differences in findings may be due to the diversification of social and cultural backgrounds in different countries and regions and the different 


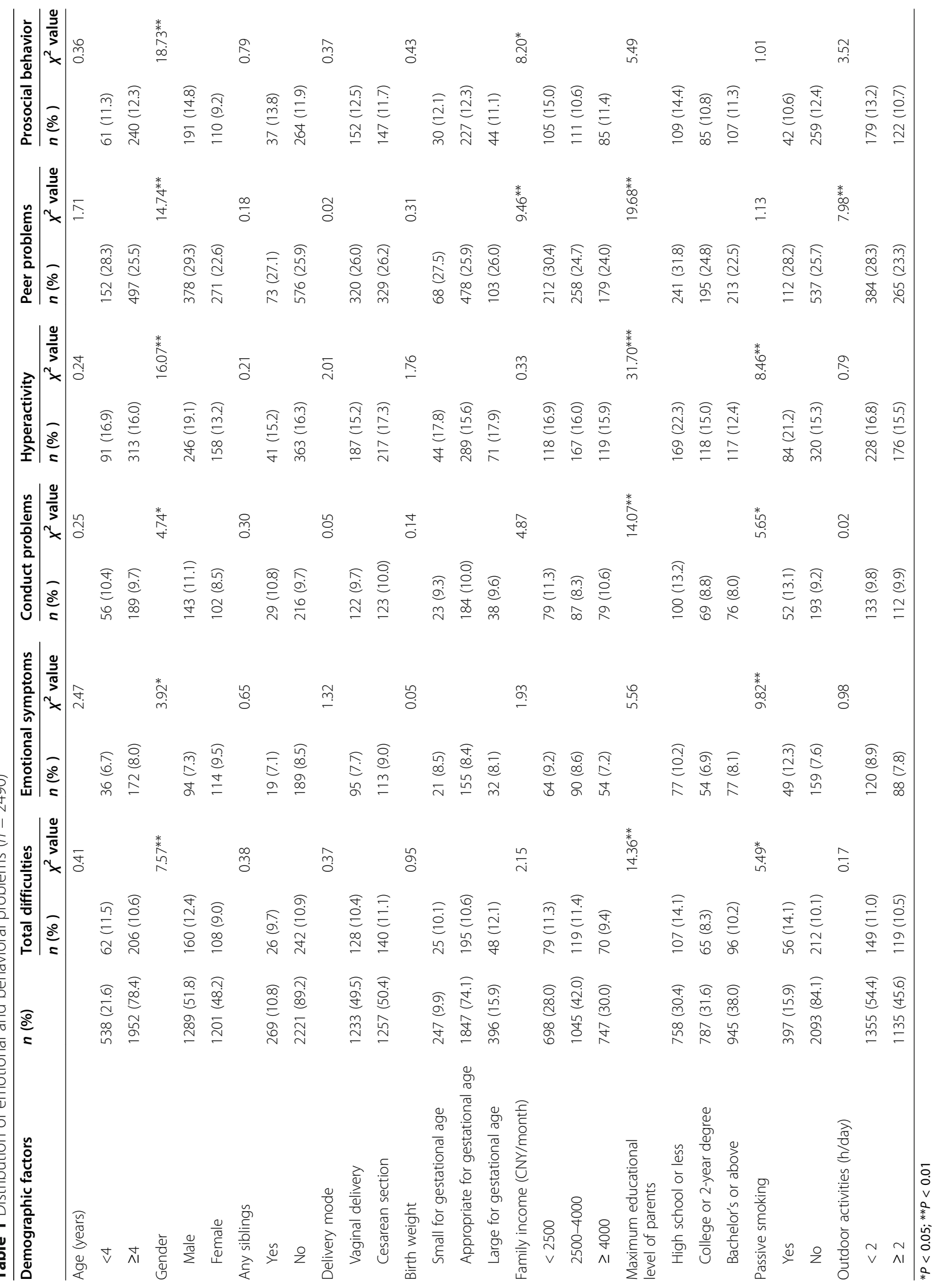


Table 2 Odds ratios (95\% confidence intervals) of emotional and behavioral problems associated with screen time $(n=2490)$

\begin{tabular}{|c|c|c|c|c|c|c|}
\hline \multirow[t]{2}{*}{ SDQ } & \multicolumn{2}{|c|}{ ST at age of 0.5} & \multicolumn{2}{|c|}{ ST at age of 2.5} & \multicolumn{2}{|c|}{ ST at age of 4} \\
\hline & $0 \mathrm{~h} /$ day & $>0 \mathrm{~h} /$ day & $\leq 2 \mathrm{~h} /$ day & $>2 \mathrm{~h} /$ day & $\leq 2 \mathrm{~h} /$ day & $>2$ h/day \\
\hline No. of participants (\%) & $1353(54.3)$ & $1137(45.7)$ & $1108(44.5)$ & $1382(55.5)$ & $1630(65.5)$ & $860(34.5)$ \\
\hline \multicolumn{7}{|l|}{ Total difficulties } \\
\hline Crude model & Ref & $1.30(1.01-1.67)^{*}$ & Ref & $1.34(1.04-1.74)^{*}$ & Ref & $1.76(1.36-2.28)^{* *}$ \\
\hline Adjusted model ${ }^{a}$ & Ref & $1.23(0.95-1.60)^{b}$ & Ref & $1.29(0.98-1.68)$ & Ref & $1.72(1.31-2.24)^{* *}$ \\
\hline \multicolumn{7}{|l|}{ Emotional symptoms } \\
\hline Crude model & Ref & $1.43(1.07-1.90)^{*}$ & Ref & $1.10(0.82-1.46)$ & Ref & $1.43(1.07-1.91)^{*}$ \\
\hline Adjusted model & Ref & $1.36(1.02-1.83)^{*}$ & Ref & $1.06(0.79-1.43)$ & Ref & 1.38 (0.99-1.90) \\
\hline \multicolumn{7}{|l|}{ Conduct problems } \\
\hline Crude model & Ref & $1.41(1.08-1.84)^{*}$ & Ref & $1.29(0.99-1.70)$ & Ref & $1.95(1.49-2.54)^{* *}$ \\
\hline Adjusted model & Ref & $1.29(0.99-1.70)$ & Ref & $1.20(0.91-1.58)$ & Ref & $1.81(1.38-2.39)^{* *}$ \\
\hline \multicolumn{7}{|l|}{ Hyperactivity } \\
\hline Crude model & Ref & $1.43(1.16-1.77)^{* *}$ & Ref & $1.42(1.14-1.76)^{* *}$ & Ref & $1.52(1.22-1.89)^{* *}$ \\
\hline Adjusted model & Ref & $1.31(1.06-1.64)^{*}$ & Ref & $1.31(1.04-1.63)^{*}$ & Ref & $1.38(1.10-1.74)^{* *}$ \\
\hline \multicolumn{7}{|l|}{ Peer problems } \\
\hline Crude model & Ref & $1.21(0.93-1.34)$ & Ref & $1.12(0.94-1.34)$ & Ref & $1.39(1.16-1.67)^{* *}$ \\
\hline Adjusted model & Ref & $1.04(0.87-1.25)$ & Ref & $1.05(0.87-1.27)$ & Ref & $1.36(1.12-1.65)^{* *}$ \\
\hline \multicolumn{7}{|l|}{ Prosocial behavior } \\
\hline Crude model & Ref & $1.00(0.79-1.28)$ & Ref & $0.99(0.78-1.27)$ & Ref & $1.43(1.11-1.82) * *$ \\
\hline Adjusted model & Ref & $0.97(0.75-1.24)$ & Ref & $0.96(0.75-1.23)$ & Ref & $1.46(1.13-1.89) * *$ \\
\hline
\end{tabular}

$S D Q$ Strength and Difficulties Questionnaire

${ }^{a}$ Adjustment for age, gender, number of siblings, delivery model, birth weight, maximum educational level of parents, family income, passive smoking, outdoor activities

${ }^{\mathrm{b}} \mathrm{OR}$ odd ratio, $\mathrm{Cl}$ confidence interval

${ }^{*} P<0.05$; ${ }^{*} P<0.01$

classification criteria of questionnaires. Children with low parental educational levels and those who are exposed to passive smoking are more likely to report emotional and behavioral problems. Therefore, attention should be paid regarding the impact of the family environment and exposure to secondhand smoking on children's health [26].

Previous studies have shown that high levels of ST are associated with poorer outcomes, such as aggression [27], inattention problems [28], prosocial behavior [29], and emotional problems [30], which are consistent with our findings. We found negative effects of high ST at an earlier age on later emotional and behavioral problems. Few longitudinal studies have investigated the association between ST for infants and toddlers and the risk of emotional and behavioral problems. A prospective cohort study showed that the longer children use electronic media in early childhood, the worse their wellbeing, but this was concluded using the emotional symptoms and peer problems subscale of the SDQ [31]. We found that the exposure to electronic media has a negative effect on children's attention problems at each age group. Previous studies have shown that exposure to television screens in children aged 18 months can impair attention at age 30 months [29], and exposure to higher levels of electronic media at age 29 months can predict poor academic outcomes for school-age children, which requires concentration in class [32]. Furthermore, early childhood video behavior is considered to have developmental continuity [33], and $16.5 \%$ of children in our study sustained a high screen time. We also found that the negative effect of sustained high ST exposure from 6 months to 4 years of age is stronger than that of concurrent exposure or early exposure only, consistent with the results of Mistry et al.'s study [34], and sustained exposure is a risk factor for behavioral problems. Therefore, the findings of this study reinforce the negative impact of electronic media use on children's psychological health.

Gender differences were identified in the occurrence of emotional and behavioral problems. In line with prior studies, boys were more prone to report total difficulties, conduct problems, hyperactivity problems, peer problems, and prosocial behavior than girls, while girls were more likely than boys to report emotional problems [35, 36]. In addition, there were no gender differences in the health effects of early childhood electronic media exposure in subsequent emotional and behavioral problems, which is inconsistent with the findings of Hinkley et al.'s study 
Table 3 Odds ratios (95\% confidence intervals) of emotional and behavioral problems associated with screen time stratified by gender $(n=2490)$

\begin{tabular}{|c|c|c|c|c|c|c|}
\hline \multirow[t]{2}{*}{ SDQ } & \multicolumn{2}{|c|}{ ST at age of 0.5} & \multicolumn{2}{|c|}{ ST at age of 2.5} & \multicolumn{2}{|c|}{ ST at age of 4} \\
\hline & $0 \mathrm{~h} /$ day & $>0 \mathrm{~h} /$ day & $\leq 2 \mathrm{~h} /$ day & $>2$ h/day & $\leq 2 \mathrm{~h} /$ day & $>2$ h/day \\
\hline \multicolumn{7}{|c|}{ Total difficulties } \\
\hline Boys $^{a}$ & Ref & $1.12(0.79-1.57)^{\mathrm{b}}$ & Ref & $1.23(0.87-1.75)$ & Ref & $1.62(1.14-2.30)^{* *}$ \\
\hline Girls ${ }^{a}$ & Ref & $1.38(0.92-2.09)$ & Ref & $1.39(0.91-2.11)$ & Ref & $1.89(1.25-2.87)^{* *}$ \\
\hline $\mathrm{ROR}$ & & $0.81(0.48-1.39)$ & & $0.88(0.51-1.53)$ & & $0.86(0.50-1.48)$ \\
\hline \multicolumn{7}{|c|}{ Emotional symptoms } \\
\hline Boys & Ref & $1.15(0.75-1.78)$ & Ref & $1.09(0.73-1.63)$ & Ref & 1.39 (0.89-2.16) \\
\hline Girls & Ref & $1.55(1.04-2.32)^{*}$ & Ref & $1.04(0.69-1.55)$ & Ref & $1.47(0.97-2.22)$ \\
\hline $\mathrm{ROR}$ & & $0.74(0.41-1.34)$ & & $1.05(0.59-1.85)$ & & $0.95(0.52-1.73)$ \\
\hline \multicolumn{7}{|c|}{ Conduct problems } \\
\hline Boys & Ref & $1.12(0.78-1.60)$ & Ref & $1.17(0.82-1.69)$ & Ref & $1.76(1.22-2.54)^{* *}$ \\
\hline Girls & Ref & $1.54(1.01-2.35)^{*}$ & Ref & $1.26(0.83-1.94)$ & Ref & $1.96(1.28-3.00)^{* *}$ \\
\hline $\mathrm{ROR}$ & & $0.73(0.42-1.27)$ & & $0.93(0.53-1.62)$ & & $0.90(0.51-1.58)$ \\
\hline \multicolumn{7}{|c|}{ Hyperactivity } \\
\hline Boys & Ref & $1.36(1.02-1.80)^{*}$ & Ref & $1.27(0.95-1.71)$ & Ref & $1.41(1.05-1.89)^{*}$ \\
\hline Girls & Ref & $1.26(0.89-1.78)$ & Ref & $1.36(0.96-1.95)$ & Ref & $1.35(0.95-1.94)$ \\
\hline $\mathrm{ROR}$ & & $1.08(0.69-1.69)$ & & $0.93(0.59-1.48)$ & & $1.04(0.66-1.66)$ \\
\hline \multicolumn{7}{|c|}{ Peer problems } \\
\hline Boys & Ref & $1.12(0.88-1.44)$ & Ref & $0.95(0.74-1.23)$ & Ref & $1.43(1.11-1.85)^{* *}$ \\
\hline Girls & Ref & $0.94(0.71-1.24)$ & Ref & $1.21(0.91-1.60)$ & Ref & $1.28(0.96-1.73)$ \\
\hline $\mathrm{ROR}$ & & $1.19(0.82-1.73)$ & & $0.79(0.54-1.15)$ & & $1.12(0.76-1.65)$ \\
\hline \multicolumn{7}{|c|}{ Prosocial behavior } \\
\hline Boys & Ref & $0.83(0.61-1.14)$ & Ref & $1.01(0.73-1.38)$ & Ref & $1.62(1.17-2.24)^{* *}$ \\
\hline Girls & Ref & $1.23(0.82-1.84)$ & Ref & $0.90(0.60-1.35)$ & Ref & $1.26(0.83-1.93)$ \\
\hline ROR & & $0.67(0.40-1.12)$ & & $1.12(0.67-1.88)$ & & $1.29(0.75-2.19)$ \\
\hline
\end{tabular}

$S D Q$ Strength and Difficulties Questionnaire, $R O R$ ratio of two odds ratio in boys versus girls

${ }^{a}$ Adjustment for age, number of siblings, delivery model, birth weight, maximum educational level of parents, family income, passive smoking, outdoor activities

${ }^{\mathrm{b}} \mathrm{OR}$ odd ratio, $\mathrm{Cl}$ confidence interval

${ }^{*} P<0.05 ;{ }^{* *} P<0.01$

[31]. But we can see that girls seem to be more susceptible to screen time than boys. The mechanism of these gender differences has not been well understood and may be due to different levels of trait neuroticism; girls tend to ruminate more frequently than boys [37].

The mechanism of ST on emotional and behavioral problems is unclear. Some studies suggest that, according to the social learning theory, children can easily learn what is on a screen by observing and imitating [38]. In addition, the stimulation of electronic media for children is so diverse, and the focus of most programs changes rapidly, which can impair children's ability to concentrate [16]. An animal model study suggested that excessive visual and auditory stimulation of newborn

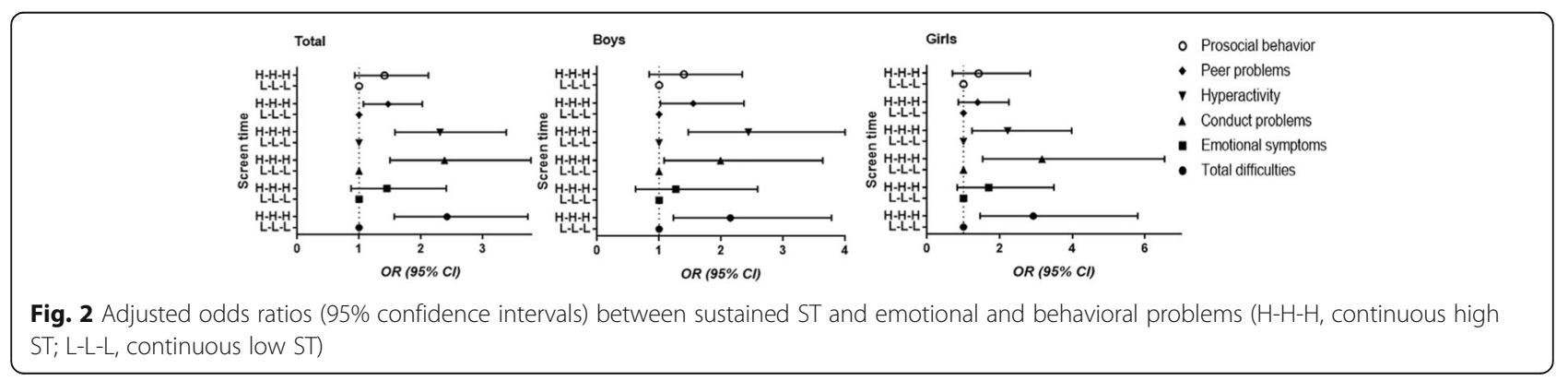


mice can have a significant adverse effect on its subsequent neurocognitive function [39]. Nonetheless, additional research is needed to further investigate such potential mechanisms.

The strengths of the study is its being a longitudinal study and that it analyzed boys and girls separately. The survey was conducted by maternal and child healthcare professionals, and the questionnaire was authentic and complete. Except for general demographic sociological characteristics, pregnancy and birth data were also included as potential confounders. However, there are still some limitations to this study. First, ST were reported by parents and thus the data may have been inaccurate, despite this, however, as most of the ST exposure of infants and young children occurs at home, there is good reason to believe that ST was accurately measured. Second, there are many factors that may affect children's emotional and behavioral problems which were not included in this study as controlled factors, such as maternal emotional problems [40] and parenting style [41], we have not controlled these factors. Third, the occurrence of selection bias due to loss-to-follow-up also limits our study. At 4 years of age, 2492 children were included in the study, the follow-up rate was $76.2 \%$. Baseline birth information and general demographic characteristics of the lost and followed children were analyzed, and the results showed that there were no significant differences in gender and parental education. In addition, we did not consider the impact of video content, and previous studies have shown that electronic media content were associated with children's attention problems [42] and aggressive behavior [27].

\section{Conclusions}

This study indicates that children with high ST exposure at an early age are prone to emotional and behavioral problems. In particular, sustained high ST exposure is a risk factor for behavioral problems. Therefore, parents and kindergarten should pay attention to limiting the ST of children. Further research is also needed to explore the possible mechanisms of this association.

\section{Supplementary Information}

The online version contains supplementary material available at https://doi. org/10.1186/s12199-020-00926-w.

Additional file 1: Table S1. Demographic characteristics between lossto-follow up and follow up groups. Table S2. Odds ratios (95\% confidence intervals) of emotional and behavioral problems associated with screen time (normal only vs. abnormal groups). Table S3. Odds ratios ( $95 \%$ confidence intervals) of emotional and behavioral problems associated with screen time stratified by gender (normal only vs. abnormal groups). Table S4. Adjusted odds ratios (95\% confidence intervals) between sustained ST and emotional and behavioral problems (normal only vs. abnormal groups).

\section{Acknowledgements}

The authors would like to acknowledge all of the participants and the Ma'anshan Maternal and Child Health (MCH) Hospital voluntary staff.

\section{Authors' contributions}

Fangbiao Tao and Shuangqin Yan conceptualized and designed the study. Fangbiao Tao obtained the fund. Wenwen Liu carried out statistical analysis and drafted the initial manuscript. Xiaoyan Wu and Kun Huang critically reviewed the manuscript. Liya Ma, Hui Cao, and Hong Gan did the investigation and data collection. All authors have read and agreed to the published version of the manuscript. The authors read and approved the final manuscript.

\section{Funding}

This study was funded by the National Natural Science Foundation of China [grant number: 81573168].

\section{Availability of data and materials}

The data used to derive our conclusions are unsuitable for public deposition due to ethical restrictions imposed by the institutional ethics committee, as the data contain sensitive information on participants and facilities.

\section{Ethics approval and consent to participate}

The study was approved by the Ethics Committee of the Anhui Medical University. And informed consent was signed by all the parents or guardians of participants.

\section{Consent for publication}

N/A.

\section{Competing interests}

The authors declare that there is no conflict of interests.

\section{Author details}

'Department of Maternal, Child, and Adolescent Health, School of Public Health, Anhui Medical University, No 81 Meishan Road, Hefei 230032, Anhui, China. ${ }^{2}$ MOE Key Laboratory of Population Health Across Life Cycle, No 81 Meishan Road, Hefei 230032, Anhui, China. ${ }^{3} \mathrm{NHC}$ Key Laboratory of Study on Abnormal Gametes and Reproductive Tract, No 81 Meishan Road, Hefei 230032, Anhui, China. ${ }^{4}$ Anhui Provincial Key Laboratory of Population Health and Aristogenics, No 81 Meishan Road, Hefei 230032, Anhui, China.

${ }^{5}$ Maanshan Maternal and Child Healthcare Center, Maanshan 243000, Anhui, China.

Received: 23 September 2020 Accepted: 20 December 2020 Published online: 07 January 2021

\section{References}

1. Bach SL, Molina ML, Amaral P, Reyes AN, Jansen K, Silva R, Motta J. Emotional and behavioral problems: a school-based study in southern Brazil. Trends Psychiatry Psychother. 2019;41(3):211-7. https://doi.org/10.1590/ 2237-6089-2017-0119.

2. Kieling C, Baker-Henningham H, Belfer M, Conti G, Ertem I, Omigbodun O, Rohde LA, Srinath S, Ulkuer N, Rahman A. Child and adolescent mental health worldwide: evidence for action. Lancet. 2011;378(9801):1515-25. https://doi.org/10.1016/S0140-6736(11)60827-1.

3. D'Souza S, Underwood L, Peterson ER, Morton SMB, Waldie KE. Persistence and change in behavioural problems during early childhood. BMC Pediatr. 2019;19(1):259. https://doi.org/10.1186/s12887-019-1631-3.

4. Rajmil L, Palacio-Vieira JA, Herdman M, López-Aguilà S, Villalonga-Olives E, Valderas JM, Espallargues M, Alonso J. Effect on health-related quality of life of changes in mental health in children and adolescents. Health Qual Life Outcomes. 2009;7:103. https://doi.org/10.1186/1477-7525-7-103.

5. Wu X, Tao S, Rutayisire E, Chen Y, Huang K, Tao F. The relationship between screen time, nighttime sleep duration, and behavioural problems in preschool children in China. Eur Child Adolesc Psychiatry. 2017;26(5):541-8. https://doi.org/10.1007/s00787-016-0912-8.

6. Lissak G. Adverse physiological and psychological effects of screen time on children and adolescents: literature review and case study. Environ Res. 2018;164:149-57. https://doi.org/10.1016/j.envres.2018.01.015.

7. Khan A, Uddin R, Burton NW. Insufficient physical activity in combination with high screen time is associated with adolescents' psychosocial 
difficulties. Int Health. 2018;10(4):246-51. https://doi.org/10.1093/inthealth/ ihy019.

8. LeBlanc AG, Katzmarzyk PT, Barreira TV, Broyles ST, Chaput JP, Church TS, Fogelholm M, Harrington DM, Hu G, Kuriyan R, et al. Correlates of total sedentary time and screen time in 9-11 year-old children around the world: The International Study of Childhood Obesity. PLoS One. 2015;10(6): e0129622. https://doi.org/10.1371/journal.pone.0129622.

9. Parkes A, Sweeting $H$, Wight $D$, Henderson M. Do television and electronic games predict children's psychosocial adjustment? Longitudinal research using the UK Millennium Cohort Study. Arch Dis Child. 2013;98(5):341-8. https://doi.org/10.1136/archdischild-2011-301508.

10. American Academy of Pediatrics, Committee on Public Education. American Academy of Pediatrics: Children, adolescents, and television. Pediatrics. 2001;107(2):423-6. https://doi.org/10.1542/peds.107.2.423.

11. Duch H, Fisher EM, Ensari I, Font M, Harrington A, Taromino C, Yip J, Rodriguez C. Association of screen time use and language development in Hispanic toddlers: a cross-sectional and longitudinal study. Clin Pediatr. 2013;52(9):857-65. https://doi.org/10.1177/0009922813492881.

12. Tomopoulos S, Dreyer BP, Berkule S, Fierman AH, Brockmeyer C, Mendelsohn AL. Infant media exposure and toddler development. Arch Pediatr Adolesc Med. 2010;164(12):1105-11. https://doi.org/10.1001/ archpediatrics.2010.235.

13. Hallal PC, Andersen LB, Bull FC, Guthold R, Haskell W, Ekelund U, Lancet Physical Activity Series Working Group. Global physical activity levels: surveillance progress, pitfalls, and prospects. Lancet. 2012;380(9838):247-57. https://doi.org/10.1016/50140-6736(12)60646-1.

14. Gunnell KE, Flament MF, Buchholz A, Henderson KA, Obeid N, Schubert N, Goldfield GS. Examining the bidirectional relationship between physical activity, screen time, and symptoms of anxiety and depression over time during adolescence. Prev Med. 2016;88:147-52. https://doi.org/10.1016/j. ypmed.2016.04.002.

15. McDonald SW, Kehler HL, Tough SC. Risk factors for delayed socialemotional development and behavior problems at age two: results from the All Our Babies/Families (AOB/F) cohort. Health Sci Rep. 2018;1(10):e82. https://doi.org/10.1002/hsr2.82.

16. Tamana SK, Ezeugwu V, Chikuma J, Lefebvre DL, Azad MB, Moraes TJ, Subbarao P, Becker AB, Turvey SE, Sears MR, et al. Screen-time is associated with inattention problems in preschoolers: results from the CHILD birth cohort study. PLoS One. 2019;14(4):e0213995. https://doi.org/10.1371/ journal.pone.0213995.

17. Yamada H, Sadato N, Konishi Y, Muramoto S, Kimura K, Tanaka M, Yonekura $Y$, Ishii $Y$, Itoh H. A milestone for normal development of the infantile brain detected by functional MRI. Neurology. 2000;55(2):218-23. https://doi.org/ 10.1212/wnl.55.2.218

18. Aishworiya R, Cai S, Chen HY, Phua DY, Broekman BFP, Daniel LM, Chong YS, Shek LP, Yap F, Chan SY, et al. Television viewing and child cognition in a longitudinal birth cohort in Singapore: the role of maternal factors. BMC Pediatr. 2019;19(1):286. https://doi.org/10.1186/s12887-019-1651-z.

19. Gao H, Zhu YD, Xu YY, Zhang YW, Yao HY, Sheng J, Jin ZX, Ren LL, Huang K, Hao $J \mathrm{H}$, et al. Season-dependent concentrations of urinary phthalate metabolites among Chinese pregnant women: Repeated measures analysis. Environ Int. 2017;104:110-7. https://doi.org/10.1016/j.envint.2017.03.021.

20. Goodman R, Renfrew D, Mullick M. Predicting type of psychiatric disorder from Strengths and Difficulties Questionnaire (SDQ) scores in child mental health clinics in London and Dhaka. Eur Child Adolesc Psychiatry. 2000;9(2): 129-34. https://doi.org/10.1007/s007870050008.

21. Jianhua K, Yasong D, Liming X. Reliability and validity of "children strengths and difficulties questionnaire" in Shanghai norm. Shanghai Arch Psychiatry. 2005;17(1):25-8 http://kns.cnki.net/KCMS/detail/detail.aspx?FileName=JSYI2 00501006\&DbName $=$ CJFQ2005.

22. Jansen PW, Mensah FK, Clifford SA, Tiemeier H, Nicholson JM, Wake M. Development of mental health problems and overweight between ages 4 and 11 years: a population-based longitudinal study of Australian children. Acad Pediatr. 2013;13(2):159-67. https://doi.org/10.1016/j.acap.2012.12.001.

23. Lee CH, Kim YJ, Lee SB, Yoo CK, Kim HM. Psychological screening for the children with habitual snoring. Int J Pediatr Otorhinolaryngol. 2014;78(12): 2145-50. https://doi.org/10.1016/j.jpporl.2014.09.026.

24. Tong L, Shinohara R, Sugisawa Y, Tanaka E, Watanabe T, Koeda T, Anme T. Buffering effect of parental engagement on the relationship between corporal punishment and children's emotional/behavioral problems. Pediatr Int. 2015;57(3):385-92. https://doi.org/10.1111/ped.12604.
25. Ren Y, Yao X, Liu Y, Liu S, Li X, Huang Q, Liu F, Li N, Lu Y, Yuan Z, et al. Outdoor air pollution pregnancy exposures are associated with behavioral problems in China's preschoolers. Environ Sci Pollut Res Int. 2019;26(3): 2397-408. https://doi.org/10.1007/s11356-018-3715-2.

26. Poole-Di Salvo E, Liu YH, Brenner S, Weitzman M. Adult household smoking is associated with increased child emotional and behavioral problems. J Dev Behav Pediatr. 2010;31(2):107-15. https://doi.org/10.1097/DBP. Ob013e3181cdaad6.

27. Manganello JA, Taylor CA. Television exposure as a risk factor for aggressive behavior among 3-year-old children. Arch Pediatr Adolesc Med. 2009; 163(11):1037-45. https://doi.org/10.1001/archpediatrics.2009.193.

28. Suchert V, Hanewinkel $R$, Isensee B. Sedentary behavior and indicators of mental health in school-aged children and adolescents: a systematic review. Prev Med. 2015;76:48-57. https://doi.org/10.1016/j.ypmed.2015.03.026.

29. Cheng S, Maeda T, Yoichi S, Yamagata Z, Tomiwa K, Japan Children's Study Group. Early television exposure and children's behavioral and social outcomes at age 30 months. J Epidemiol. 2010;20(Suppl 2):S482-9. https:// doi.org/10.2188/jea.je20090179.

30. Twenge JM, Campbell WK. Associations between screen time and lower psychological well-being among children and adolescents: evidence from a population-based study. Prev Med Rep. 2018;12:271-83. https://doi.org/10. 1016/j.pmedr.2018.10.003.

31. Hinkley T, Verbestel V, Ahrens W, Lissner L, Molnár D, Moreno LA, Pigeot I, Pohlabeln H, Reisch LA, Russo P, et al. Early childhood electronic media use as a predictor of poorer well-being: a prospective cohort study. JAMA Pediatr. 2014;168(5):485-92. https://doi.org/10.1001/jamapediatrics.2014.94.

32. Pagani LS, Fitzpatrick C, Barnett TA, Dubow E. Prospective associations between early childhood television exposure and academic, psychosocial, and physical well-being by middle childhood. Arch Pediatr Adolesc Med. 2010;164(5):425-31. https://doi.org/10.1001/archpediatrics.2010.50.

33. Jones RA, Hinkley T, Okely AD, Salmon J. Tracking physical activity and sedentary behavior in childhood: a systematic review. Am J Prev Med. 2013; 44(6):651-8. https://doi.org/10.1016/j.amepre.2013.03.001.

34. Mistry KB, Minkovitz CS, Strobino DM, Borzekowski DL. Children's television exposure and behavioral and social outcomes at 5.5 years: does timing of exposure matter? Pediatrics. 2007;120(4):762-9. https://doi.org/10.1542/peds. 2006-3573.

35. Bibou-Nakou I, Markos A, Padeliadu S, Chatzilampou P, Ververidou S. Multiinformant evaluation of students' psychosocial status through SDQ in a national greek sample. Child Youth Serv Rev. 2019;96:47-54. https://doi.org/ 10.1016/j.childyouth.2018.11.022.

36. Idris IB, Barlow J, Dolan A. A longitudinal study of emotional and behavioral problems among Malaysian school children. Ann Glob Health. 2019:85(1):30. https://doi.org/10.5334/aogh.2336.

37. Eaton NR, Keyes KM, Krueger RF, Balsis S, Skodol AE, Markon KE, Grant BF, Hasin DS. An invariant dimensional liability model of gender differences in mental disorder prevalence: evidence from a national sample. J Abnorm Psychol. 2012;121(1):282-8. https://doi.org/10.1037/a0024780.

38. Reid Chassiakos YL, Radesky J, Christakis D, Moreno MA, Cross C. Health effects of media on children and adolescents. Pediatrics. 2010;138(5): e20162593. https://doi.org/10.1542/peds.2016-2593.

39. Christakis DA, Ramirez JS, Ramirez JM. Overstimulation of newborn mice leads to behavioral differences and deficits in cognitive performance. Sci Rep. 2012;2:546. https://doi.org/10.1038/srep00546.

40. Faleschini S, Rifas-Shiman SL, Tiemeier H, Oken E, Hivert MF. Associations of prenatal and postnatal maternal depressive symptoms with offspring cognition and behavior in mid-childhood: a prospective cohort study. Int J Environ Res Public Health. 2019;16(6):1007. https://doi.org/10.3390/ ijerph16061007.

41. Hosokawa R, Katsura T. Role of parenting style in children's behavioral problems through the transition from preschool to elementary school according to gender in Japan. Int J Environ Res Public Health. 2018;16(1):21. https://doi.org/10.3390/ijerph16010021.

42. Lillard AS, Peterson J. The immediate impact of different types of television on young children's executive function. Pediatrics. 2011;128(4):644-9. https://doi.org/10.1542/peds.2010-1919.

\section{Publisher's Note}

Springer Nature remains neutral with regard to jurisdictional claims in published maps and institutional affiliations. 